\title{
DESIGN THINKING IN PEDAGOGY
}

\author{
INETA LUKA \\ Turiba University, Graudu 68 \\ Riga LV-1058, Latvia \\ e-mail address: Ineta@turiba.lv
}

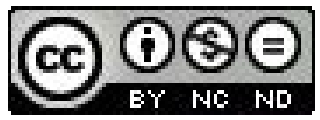

\begin{abstract}
The twenty-first century has brought lots of challenges for people in all spheres, including education. In the new context, traditional approaches often seem ineffective and therefore new tools and methods have to be applied. An alternative approach that might be useful in the given context is design thinking - the approach that originated in architecture, design and art, and nowadays is applied in many fields. It is a human-centered problem-solving approach that may be used in the teaching/learning process to develop twenty-first century skills and enhance creativity and innovation. This paper introduces readers to the origin of design thinking, its attributes and processes as well as its application in pedagogy.
\end{abstract}

Keywords: design thinking, problem-solving, creativity, innovation, teamwork, skills development

\section{INTRODUCTION}

The twenty-first century has brought many challenges for people in all spheres. The increased mobility, the world-wide web, and the instant information spread place people in previously unknown contexts and situations which require immediate analysis, decision-making and problem-solving. Traditional approaches to these often seem ineffective and therefore new tools and methods have to be applied. This also concerns pedagogy where teachers face complex and varied challenges.

In this context more and more frequently we hear the term "design thinking" "a concept used both in theory and practice" (Johansson-Sköldberg, Woodilla, \& Çetinkaya, 2013, p. 121). Design thinking is even referred to as a new paradigm for dealing with problems in many professions and fields, including IT, business, research, innovation and education (Dolak, Uebernickel, \& Brenner, 2013; Dorst, 2011).

Design thinking may be considered as a great tool to be used in the teaching/ learning process to develop twenty-first century skills. It comprises collaboration in order to solve the problems by finding and processing information taking into consideration the real world, people's experience and feedback (Ray, 2012) and applying creativity, critical thinking and communication. Moreover, this approach is characterized as "a powerful methodology for innovation" which "integrates human, business and technical factors in problem forming, solving and design" (Leifer, \& Steinert, 
2011, p. 151). It is human-centered and simultaneously uses diverse points-of-view in problem-solution (Leifer, \& Steinert, 2011).

However, the recent trend to adopt and apply design practices to other fields requires clear and definite knowledge about design thinking (Dorst, 2011). Therefore, it is essential to understand this phenomenon as well as to learn how to develop corresponding knowledge and skills and how to apply them in practice.

This paper deals with the origin of design thinking, its characteristics and processes, its use in pedagogy and offers ideas for the development of design thinking skills in the teaching/learning process.

\section{ORIGIN OF DESIGN THINKING}

The discourse of design thinking originated in architecture, design and art, and later was also applied in the field of management (Johansson, \& Woodilla, 2009). In the academic field the term has been known for thirty years and initially it was associated with the way designers think (Johansson, \& Woodilla, 2009). The term was first used in 1987 by Rowe when he published a book titled Design Thinking (Rowe, 1987), although Simon analyzed the nature of design already eighteen years before the term "design thinking" had been introduced (Simon, 1969).

Since then, based on "theories and models from design methodology, psychology, education, etc." (Dorst, 2011, p. 521) various models have been created. The sources point to the growth of popularity of scholarly works on design thinking in the 1980's - 1990's, with the largest number of works published in 2009 (Johansson-Sköldberg, et.al, 2013).

Theoretical perspectives of design thinking have been categorized into five sub-discourses: 1 ) design thinking as the creation of artifacts; 2 ) design thinking as a reflexive practice; 3) design thinking as a problem-solving activity; 4) design thinking as a way of reasoning/making sense of things; 5) design thinking as the creation of meaning (Johansson-Sköldberg, et.al, 2013).

Simon (1969), the founder of artificial intelligence, "distinguished between activities that create something new and activities that deal with existing reality" (Johansson-Sköldberg, et.al, 2013, p. 124). In this approach the focus was on creation and the way of changing and/ or adapting the existing conditions to the ones that would comply with the current context.

The second sub-discourse is associated with Schön (1983) who emphasized the role of reflection in design thinking. Moreover, reflection was interpreted as the core of design work and as a part of practice. Reflection is at the basis of learning and any successful activity and teachers should encourage students to reflect on their activities to come to a solution.

Design thinking as a problem-solving activity is first and foremost associated with Rittel's formulation and Buchanan's elaboration of the 'wicked problems' approach (Buchanan, 1992). According to this approach "the design process is divided into two distinct phases: problem definition and problem solution" (Buchanan, 1992, p. 15). During the first phase all the elements of the problem are identified. This is an analytic sequence. In turn, during the problem-solving phase, which is a synthetic sequence, different variants are compared and balanced against each other to create the final plan (Buchanan, 1992). The approach adopted is interpretive, emergent and explicitly embodied (Rylander, 2009).

The proponents of the fourth sub-discourse argue that design thinking is a practice-based activity and a way of making sense of things. It is common to use deductive and/or in- 
ductive thinking for problem-solving. However, design thinking applies abduction which results in a value. We can single out two forms of abduction - closed problem-solving and open problem-solving. The strategies involve the development of "a frame", which may be regarded as the "creation of a (novel) standpoint from which a problematic situation can be tackled" (Dorst, 2011, p. 525).

Finally, Krippendorff (2006) offers an approach dealing with design thinking as the creation of meaning rather than artifact (cf. Simon, 1969). In this approach "meaning is the core of the design process and the artifact becomes a medium for communicating these meanings" (Johansson-Sköldberg, et.al, 2013, p. 126).

Concerning the afore-mentioned sub-discourses of design thinking, it can be concluded that the following ones may refer to pedagogy as well: design thinking as a reflexive practice, design thinking as a problem-solving activity and design thinking as a way of reasoning. These are the features that are closely connected with such generic competences as problem solving, critical thinking and creativity, the development of which is enhanced at school.

\section{CHARACTERISTICS OF DESIGN THINKING}

Design thinking is both a process and a mindset. Scholars (Baeck, \& Gremett, 2012) single out nine attributes or characteristics of design thinking: 1) ambiguity; 2) collaboration; 3) constructiveness; 4) curiosity; 5) empathy; 6) holism; 7) iteration; 8) non-judgmental way; 9) openness.

Ambiguity means that for one phenomenon more than one possible meaning or explanation exists. In design thinking ambiguity is associated with a person's state of being comfortable in unclear situations. Design thinking involves collaboration at certain issues across disciplines in interdisciplinary teams. Design thinking is constructive thinking as it is a solution-based approach that looks for a better outcome. It means empathy as the focus is on user needs. At the same time it is holistic because it looks at a wider context for the customer. As design thinking process is not linear but cyclical, and each cycle is built upon the previous one, it is iterative. On top of that, the method encourages "outside the box thinking" to come to a creative and innovative outcome. (Baeck, \& Gremett, 2012; Waloszek, 2012)

Efeoglu, Møller, Sérié, Boer (2013) based on the ideas of Brown (2008) define design thinking as "a human-centred problem solving method that mostly leads to radical innovative solution in terms of the feasibility, desirability and viability of products or services" (Efeoglu, et.al, 2013, p. 241).

In turn, Oster (2008) describing design thinking mentions its three attributes that help ensure its operational efficiency. It is abductive, inclusive and problem-based. Design thinking is described as abductive because it "reaches well beyond deductive and inductive reasoning to build up a mountain of possible answers" (Oster, 2008, p. 111).

On the one hand, design thinking is obverse of scientific thinking. The difference lies in terms of the nature of the hypothesis they evolve around. Both, scientific thinking and design thinking depend on generating and testing hypotheses. The scientific method searches for the answer to "what is", whereas design thinking refers to "what might $\mathrm{be}^{\prime \prime}$ in the future. (Owen, 2005; Rylander, 2009) On the other hand, design thinking complements scientific thinking as creativity and a range of its other attributes have a distinct value to decision makers (Owen, 2007) helping them to attain the goal.

As previously mentioned, design thinking is a solution-based approach to solve the so-called "wicked problems". "The wicked problems approach was formulated by 
Horst Rittel in the 1960s, when design methodology was a subject of intense interest" (Buchanan, 1992, p. 15). By wicked problems he understood the problems which were ill-formulated, where the information was confusing and where many clients and decision makers with opposite opinions existed (Buchanan, 1992). Rittel identified ten properties of "wicked problems" (Rittel, \& Webber, 1972) which reveal that the problems that have to be solved do not have a definite formulation, they are unique and they can be solved in various ways. Moreover, none of the problem-solutions is true or false and none of the problem solvers is right or wrong as design thinking welcomes divergent thinking and creative and innovative ideas.

Another characteristic of design thinking is connected with the "A-Ha Moment". According to Cross (2006) the "A-Ha Moment" is a point in the cycle in which synthesis and divergent thinking, analysis and convergent thinking and the problem meet. This is a focal point as by both, reflecting and considering the future possibilities, the focus is becoming clear and the final product can be constructed. Moreover, at this moment the solution seems so evident that the people involved in the process cannot even understand how such a simple solution had not come to their minds earlier.

The main feature of design thinking is creativity that helps to solve "wicked problems" and reach the "A-Ha Moment". But besides creativity, Owen (2005) distinguishes fourteen other characteristics of design thinking. The most significant ones are as follows:

- Conditioned inventiveness - "what" questions are more important than "why" questions as the goal is inventing;

- Human-centered focus - designers have to take into consideration clients' needs when creating a product;

- Environment-centered concern in order to guarantee sustainability;

- Bias for adaptivity means applying an approach of accepting adaptive solutions fitting to the users' evolving needs wherever possible;

- Predisposition toward multi-functionality as problem-solutions need not be mono-functional;

- Systemic vision as design thinking is holistic;

- View of the generalist - for inventive creativity, contrary to the accustomed specialization, the wider the knowledge base, the more creative solution can be made;

- Affinity for teamwork because multi-disciplinary teams ensure such characteristic abilities as generalization, communication across disciplines, working systematically with qualitative information and visualizing concepts.

Owen (2006, p. 5) also adds that "these special characteristics of design thinking are not normally discussed in a university catalog. Indeed, they are seldom taught explicitly. Rather, they are acquired almost unconsciously as tacit knowledge in school projects or on the job".

Additionally, Brown (2008) emphasizes the following attributes as core attributes of design thinking: empathy, integrative thinking, optimism, experimentalism and collaboration.

In fact, these attributes are in line with the ones defined by Owen $(2005 ; 2006)$ and they are all significant in order to ensure the success of innovation. 


\title{
DESIGN THINKING PROCESSES
}

\begin{abstract}
"Design process is the way in which methods come together through a series of actions, events or steps" (Waloszek, 2012).

Initially, Simon (1969) introduced the following seven stages of design thinking process: 1) define; 2) research; 3) ideate; 4) prototype; 5) choose; 6) implement; 7) learn. First of all, it is essential to define the issue to be resolved and the audience. Next, research has to be conducted comprising analysis of the history, existing obstacles, examples, stakeholders' opinions. Ideation means identifying the needs and motivations of the end-users, and this process involves brainstorming. Next, it is essential to combine, expand and refine ideas in order to create several drafts and get the feedback from a diverse group of people, including end-users. The next stage involves reviewing the objectives and selecting the powerful ideas. The final stages are implementation, which comprises making task descriptions, planning tasks, determining resources and executing tasks, and learning - gathering feedback from the consumers in order to improve the product.

"Initial Design Thinking approaches were of circular nature" (Efeoglu, et.al, 2013, p. 242). Thus, Dunne and Martin (2006) perceive design thinking as a circular process to solve 'wicked problems'. They emphasize its cyclic character comprising the following phases: induction, abduction, deduction and testing. Abduction is connected with idea generation. During the next stage - deduction - consequences are predicted. Further, ideas are tested in practice and generalized during the induction phase.
\end{abstract}

Another well-known circular design thinking approach is that by Brown (2008). The scholar points out that "the design process is best described metaphorically as a system of spaces rather than a predefined series of orderly steps" (Brown, 2008, p. 88). He claims that the design thinking process is circular and it comprises three spaces: 1) inspiration; 2) ideation; 3) implementation. Inspiration motivates to search for solutions. Ideation is connected with brainstorming. During the ideation phase ideas are generated, developed and tested. Consequently, these ideas may lead to solutions. Implementation means executing the vision and introducing the output into the market. Every "project" passes through these three spaces. Moreover, projects may repeatedly pass through the inspiration and ideation phase on their way to getting implemented.

Based on Simon's design thinking process stages (Simon, 1969), several other models have been created; some of them even use the same terminology. The most notable of them are the ones produced by the Institute of Design at Stanford, the so called d.School. The iterative design thinking process scheme (Plattner, Meinel, \& Weinberg, 2009) initially comprised six stages (see Figure 1). As indicated by Efeoglu, et.al (2013) this is a sequential approach comprising multiple stages and it had also been impacted by a circular approach.

This approach categorizes the phases into two main phases: a problem and a solution. The problem phase consists of understanding, observing and expressing one's opinion, whereas the solution phase consists of ideation, prototyping and testing. This approach allows interacting between the phases which are linked directly or indirectly (Efeoglu, et.al, 2013). "The phase "point of view « serves as a hinge between all other linked phases" (Pferdt, 2009). 


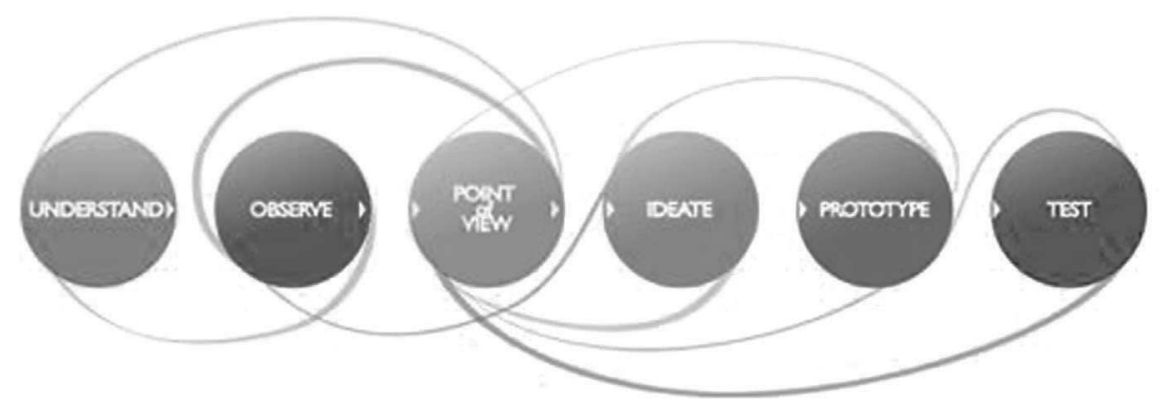

Fig. 1. Iterative Design Thinking Process

Source: Plattner, Meinel, \& Weinberg, 2009, p. 114.

In 2009 and 2010 the Institute of Design adapted their previously worked out scheme offering five phases instead of six which they call modes. The following five modes were singled out: 1) empathize; 2) define; 3) ideate; 4) prototype; 5) test. In this variant empathizing is the beginning of the design process and it comprises three activities: 1) observation of users' behavior; 2) engagement - interacting with and interviewing users; 3 ) immersion - experiencing what the users experience. The defining mode is connected with formulating an actionable problem statement. The ideation mode is the point during which we focus on idea generation. It is a process of "going wide". The prototyping is concerned with creating ideas and explorations into the physical world and testing means refining our solutions and improving them (Plattner, 2009; Plattner, 2010).

Scholars have adapted the previously worked out scheme to pedagogy suggesting that during the phase of understanding learners try to understand the problem, talk to experts and conduct research. During the stage of observing students observe people, physical spaces and places (Taking Design Thinking to Schools, n.d.). As indicated by Beckman and Barry (2007) observation helps understanding the context. The following tools are often used in observation to gather information: participant observation, non-participant observation, formal ethnographic interviews, intercepts (they join participant observation with an interview), informant diaries and virtual ethnography (studying Internet behaviour). According to the Institute of Design at Stanford during the phase of defining students have to become aware of people's needs and developing insights. During the phase of ideation students brainstorm a lot of ideas. Therefore, students have to be encouraged to brainstorm as many solutions as possible. Prototyping is a stage during which students learn to fail. The purpose of testing is to see if the solutions offered work in practice and what shall be done to improve them. Testing provides students with a feedback (Taking Design Thinking to Schools, n.d.).

The recent approach by Dolak, et.al $(2013$, p. 4) postulates that design thinking is "an approach to foster the process of human-centered idea generation and evaluation in a team context". In practice, the process starts with approaching a problem from a human perspective. The primary focus is on people and their needs, and human, business and technical factors are integrated in problem identification, problem 
solution and design. The process is a cycle. First, the problem is defined. Next, it is necessary to identify the needs, followed by brainstorming, leading to the creation of a prototype which is later tested. The constant, iterative cycle of problem identification and redefinition allows applying diverging and converging phases in the design process (Dolak, et.al, 2013). Thus, this approach is close to the earlier - circular design thinking approaches.

Analyzing the stages defined by various design thinking scholars, Waloszek (2012) comes to a conclusion that, despite some differences, the main stages in design thinking process are the same:

- Understanding the problem;

- Observing users;

- Interpreting the results;

- Generating ideas (ideating);

- Building prototypes and experimenting;

- Testing, implementing and improving the design.

Ideation and experimentation are significant in design thinking. Brown (2008) emphasizes that there are various methods to stimulate idea generation and enhance creativity. It especially refers to "outside the box" thinking as going beyond standard ideas is significant in innovation because this is where innovation starts.

The previously characterized design thinking approach is applied to design and business fields as well as management. It may also be applied to pedagogy, as thinking processes are the same.

\section{IMPLICATIONS FOR PEDAGOGY}

In education design thinking is sometimes referred to as 'design-based learning'. It is perceived as "a model for enhancing creativity, endurance, engagement and innovation" (Dolak, et.al, 2013, p. 2). The benefit of design thinking in pedagogy refers to its character which "enables students to work successfully in multi-disciplinary teams and enact positive, design-led change in the world" (Rauth, Köppen, Jobst, \& Meinel, 2010, p. 2). It is a problem-solving approach dealing with the solution of everyday problems (Rauth, Köppen, Jobst, \& Meinel, 2010). Learning and knowledge creation in design thinking education are based on highly iterative proceedings which may be associated with Kolb's experiential learning theory (Kolb, 1984; Rauth, et.al, 2010).

An ideal learning cycle must comprise the following four phases: experiencing, reflecting, thinking and acting, and a learner goes through all of them (Beckman, \& Barry, 2007). Design thinking contains all four phases. As indicated by Beckman and Barry (2007) at the basis of observations and reflections is experience. Reflections are assimilated into abstract concepts that form new implications that are tested in action and impact the creation of new experiences again, thus ensuring the feedback. The design thinking process is similar.

Owen (2007) elaborated a model of knowledge development (see: Figure 2). This model lies also at the basis of design thinking process. The scholar points out that "in any field, knowledge is generated and accumulated through action" (Owen, 2007, p. 19). He further explains that "knowledge using and knowledge building are both structured processes controlled by channels that contain and direct the production and evaluation processes" (Owen, 2007, p. 20). 


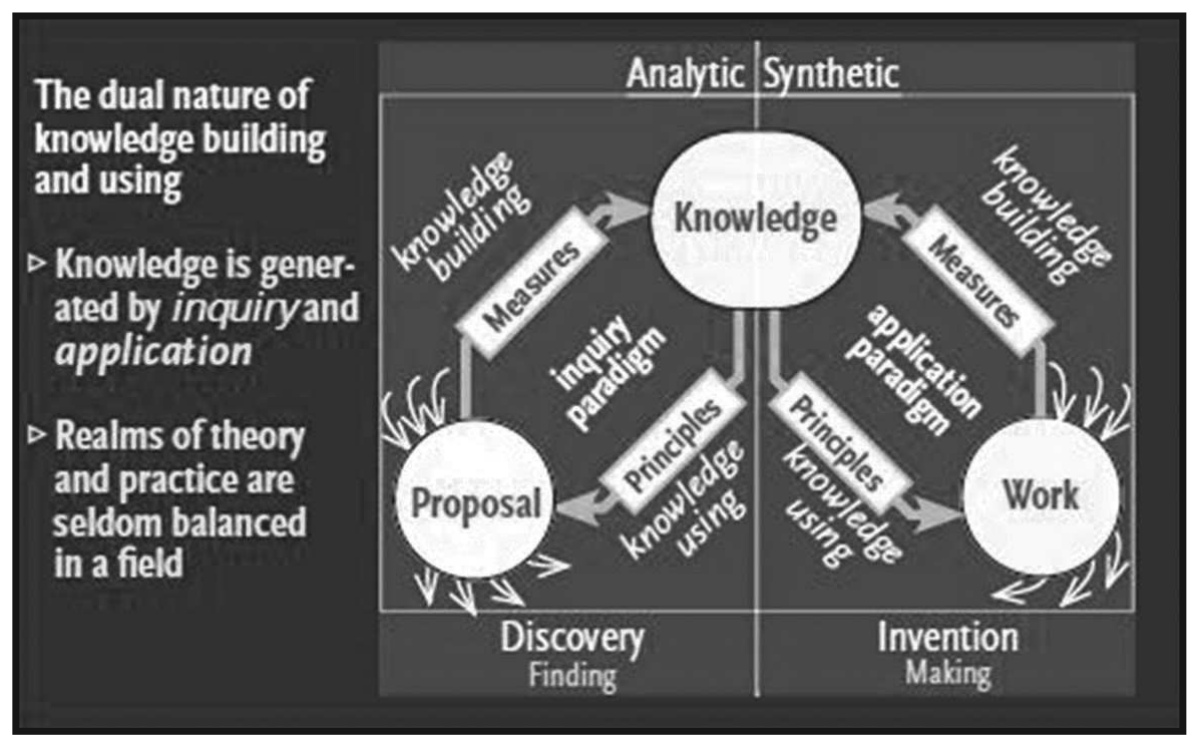

Fig. 2. Knowledge Creation

Source: Owen, 2007, p. 19, Figure 7.

The design thinking process contains analytic and synthetic elements. During the analytic phase, which is a discovery phase, the existing theories are studied, observations are made in order to find problem-solutions and this stage corresponds to the stages of understanding, observing and expressing a point of view. During the synthetic phase, idea generation continues. The application paradigm is used and it corresponds to ideation, prototyping and testing, with a focus on making. Both stages are interconnected as problem-solution starts with observation and ends with testing the variants and improving the worked out solutions. The process is an iterative cycle and during the knowledge generation the process can be repeated in loops again and again as shown in Figure 1.

Design thinking skills can be developed in various activities at school, especially in group work and projects as one of the preconditions is team working and open communication. Practitioners have tested several options. This paper summarizes the ones that may be used at any course and subject, both, at general education schools and tertiary institutions.

Ray (2012) suggests working in small groups or "Collabs" observing the following six steps: 1) identify opportunity; 2) design; 3) prototype; 4) get feedback; 5) scale and spread; 6) present. One of the basic rules concerns the way of asking the questions and expressing the opinion. Students are encouraged saying "yes" when they agree with others' ideas and "yes, but..." when they disagree. This is done in order not to discourage other students from expressing their opinion and to search alternative ideas which is essential in building prototypes. This idea demonstrates that sometimes even small changes can greatly impact the result. The activity starts with a problem that is offered for students to solve. The activity comprises six steps. 
Step 1: Identify opportunity. This may be done as a frontal activity at class or as group work. During this stage students have to find the need why the problem has to be solved, who will benefit from the solution. Then it is recommended to choose someone external, who is personally affected by the issue, to share their experiences. Students have to interview them. This can be done personally, which will involve students' out-of-class activity, or alternatively these persons may be invited to participate in the lesson in which students may question them, or interviews may be organized via Skype.

Step 2: Design process. During this phase students review the stories heard during the previous phase and brainstorm solutions. One of the ways would be to give students sticky notes and pens and let them brainstorm solutions. When students have finished brainstorming, the main themes have to be identified and at this point students form smaller groups to research the initial ideas.

Step 3: Prototype. Next, it is necessary to review the ideas and choose one prototype. This prototype has to solve one aspect of the problem. At this moment we are focusing on this one solution offered to solve a specific aspect of the given problem. Then students select the next aspect of the problem and similarly approach it. In order to visualize the thinking process it is recommended to draw a brainstorming map which clearly demonstrates this process. The brainstorming map may also be made using sticky notes and attaching them to the paper. The brainstorming map will also be useful for the next stage of the activity.

Step 4: Feedback. During this stage the groups present their solutions to external experts for feedback. It is recommended to have at least two experts from different stakeholders' groups. For example, students are discussing the problem related with an issue of young people's employability possibilities during summer holidays. One expert might be from the group of pedagogues or parents who support young people's summer work, whereas another expert might be from the group of employers who are unwilling to employ young people.

Step 5: Scale and spread. During this stage students continue working in groups to find the best solution to the feedback heard during the previous stage. In this process the teacher's help with guiding the ideas is inevitable. If the group received various comments from the experts the group can be split into several smaller groups and each group works on one issue. Then the sub-groups come together and agree on a common variant for presentation.

Step 6: Present. The groups present their problem-solutions. In order to make the process more significant for students, the people whom the students had interviewed during the first phase might be invited.

The main benefit of such an activity is the opportunity for students to solve a real-world problem and offer a problem-solution for the people who need it. They look at all possible variants, including the slightest nuances, to come to a solution. There are no bad or incorrect solutions, as according to the theory of design thinking approach every problem may be solved in different ways (Rittel, \& Webber, 1972). The challenge for the teacher might lie in the fact that this activity is time-consuming and cannot be done in one lesson/lecture. As any project-based activity, it extends over a longer period of time, so the teacher may guide the process by setting a definite timeline for each activity to be done. 
The Institute of Design at Stanford has created teaching/learning aids for different activities developing design thinking skills (Plattner, 2009; Plattner, 2010). The tools have been made in compliance with the seven mindsets or principles that design thinking follows: 1) focus on human values; 2) showing not telling; 3) creating clarity from complexity; 4) getting experimental and experiential; 5) being mindful of processes; 6) bias towards action; 7) collaborating across boundaries (Plattner, 2009). The authors offer activities for individual work and teamwork in order to prepare for the activities developing design thinking skills, such as "What? How? Why?", "Interview Preparation" for individual work and "Team-Share-and-Capture" and "Empathy Map" for group work. It also provides a methodological guide on how to use different activities, for example, "Journey Map", "2x2 Matrix", "Why-How Laddering". It also describes different ways of brainstorming and how to apply them in practice (Plattner, 2009). The authors also encourage using design principles in learning activities: 1) inviting multiple audiences; 2) extending nature of classes; 3 ) diversifying learning opportunities; 4) encouraging diversity of students; 5) extending contact beyond physical walls (Plattner, 2010). A list of activities is provided on how to implement these principles in practice. Both methodological tools (Plattner, 2009; Plattner, 2010) and various other materials found on the Internet (for example: Design Thinking for Educators, 2013; Liedtka, \& Ogilvie, 2010; McIntosh, 2014) that are used to develop design thinking skills might be applied in class as well as for self-dependent learning to diversify learning methods and material and develop design thinking skills. Teachers may adapt the existing material for their pedagogical needs and for the target groups as well as taking into consideration design thinking principles create their own teaching/learning aids as a result motivating students' learning.

\section{CONCLUSION}

"Innovation drives improvement, either incrementally by advancing existing processes or more radically by introducing new practices" (OECD, 2014, p. 3). In the context of major demographic changes - people's aging, increasing global competition and sustaining competitiveness of the EU economy, the role of innovation increases. This refers also to education which has to be modernized at all levels. It is necessary to promote excellence in education and skills development and diminish innovation skills gaps (Europe 2020 Flagship Initiative Innovation Union, 2010). The latest results of the innovation across the world (Innovation Union Scoreboard, 2014) also demonstrate that in innovation the EU with the average Global Innovation Performance Index (GIPI) 0.630 is lagging behind South Korea (GIPI 0.740), United States (GIPI 0.736) and Japan (GIPI 0.711). On the one hand, the result of the EU might seem quite good, but, on the other hand, it has to be taken into consideration that the GIPI of the EU is ranging from 0.200 to 0.750 with seventeen countries being below the EU average.

One of the ways how to increase innovation is developing design thinking skills. The term 'design thinking' was first used in 1987 and since then it has developed into an approach that extends far beyond its original application in architecture, design and art. The models designed demonstrate their applicability in pedagogy and their use at school may diversify the teaching/learning process and the study content and 
motivate students' learning. The greatest benefit of the various teaching/learning tools created in accordance with the design thinking principles is their untraditional, innovative tasks that may be completed individually or in groups and that develop students' problem-solving skills. Working in groups to solve the tasks helps students enhance team working, collaboration, communication skills and develop their design thinking skills that will later be useful in solving everyday and work-related problems in a creative and innovative way. Students practice during the studies, learn to make their own mistakes and realize that there are no right or wrong solutions to various problems. They learn to explain their opinions and listen to others' opinions, accept untraditional ideas thus welcoming innovation.

\section{REFERENCES}

Baeck, A., \& Gremett, P. (2012). Design Thinking. In: H. Degen, \& X. Yuan (Eds.), UX Best Practices: How to Achieve More Impact with User Experience (pp.229-233). New York: McGraw-Hill.

Beckman, S.L., \& Barry, M. (2007). Innovation as a Learning Process: Embedding Design Thinking. California Review Management, 50(1), Fall, 25-56.

Brown, T. (2008). Design Thinking. Harward Business Review, June 2008, 84-92.

Buchanan, R. (1992). Wicked Problems in Design Thinking. Design Issues, 8(2), Spring, 5-21.

Cross, N. (2006). Designerly Ways of Knowing. London: Springer-Verlag London Limited.

Design Thinking for Educators. (2013). New York City: Riverdale Country School \& IDEO. Retrieved from http://www.designthinkingforeducators.com/toolkit/

Dolak, F., Uebernickel, F., \& Brenner, W. (2013). Design Thinking and Design Science Research. Positioning Paper DESRIST 2013. Institute of Information Management, University of St.Gallen, HSG/IWI, 1-11.

Dorst, K. (2011). The core of 'design thinking' and its application. Design Studies, 32(6), November, 521-532. doi: 10.1016/j.destud.2011.07.006.

Dunne, D., \& Martin, R. (2006). Design thinking and how it will change management education: An interview and discussion. Academy of Management Learning \& Education, 5(4), 512-523. doi: 10.5465/ AMLE.2006.23473212.

Efeoglu, A., Møller, C., Sérié, M., \& Boer, H. (2013). Design Thinking: Characteristics and Promises. Proceedings of $14^{\text {th }}$ International CINet Conference on Business Development and Co-creation. Enschede: Continuous Innovation Network (CINet), 241-256.

Europe 2020 Flagship Initiative Innovation Unio. (2010). Communication from the Commission to the European Parliament, the Council, the European Economic and Social Committee and the Committee of the Regions, SEC(2010) 1161. Brussels, 6.10.2010, COM(2010) 546 final. Retrieved from http:/ / eur-lex.europa. $\mathrm{eu}$ /legal-content/EN/TXT/PDF/?uri=CELEX:52010DC0546\&from=EN

Innovation Union Scoreboard. (2014). Hollanders, H., \& Es-Sadki, N. (Eds.). European Union edition. doi: 10.2769/88936 Retrieved on August 8, 2014 from: http:/ / ec.europa.eu/enterprise/policies/innovation/ files/ius/ius-2014_en.pdf

Johansson, U., \& Woodilla, J. (2009). Towards an epistemological merger of design thinking. In: $8^{\text {th }}$ European Academy of Design Conference. 1-3 April 2009, the Robert Gordon University, Aberdeen, Scotland.

Johansson-Sköldberg, U., Woodilla, J., \& Çetinkaya, M. (2013). Design Thinking: Past, Present and Possible Futures. Creativity and Innovation Management, 22(2), June, 121-146. DOI: 10.1111/caim.12023

Kolb, D.A. (1984). Experiential Learning: Experience as the Source of Learning and Development. London: Prentice-Hall. Krippendorff, K. (2006). The Semantic Turn: A New Foundation for Design. Boca, Raton, FL: Taylor and Francis. 
Leifer, L.J., \& Steinert, M. (2011). Dancing with ambiguity: Causality behavior, design thinking, and tripleloop-learning. Information Knowledge Systems Management, 10, 151-173. DOI 10.3233/IKS-2012-0191

Liedtka, J.M., \& Ogilvie, T. (2010). Ten tools for design thinking. Charlottesville, VA: Darden Business Publishing, University of Virginia Darden School Foundation. UVA-BP-0550. Retrieved from: http:// www.darden.virginia.edu/web/uploadedFiles/Darden/Batten_Institute/BP-0550.pdf

McIntosh, E. (2014). Design Thinking: Tools to help make thinking visible. Retrieved from: http://notosh.com/ lab/design-thinking-tools-to-help-make-thinking-visible-nesta-diy/

OECD (2014). S. Vincent-Lancrin, K. Kärkkäinen, S. Pfotenhauer, A. Atkinson, G. Jacotin, M. Rimini. (eds.). Measuring Innovation in Education: A New Perspective, Educational Research and Innovation. OECD Publishing, Centre for Educational Research and Innovation, DOI:10.1787/9789264215696-en Retrieved from: http://www.keepeek.com/Digital-Asset-Management/oecd/education/measuring-innovationin-education_9789264215696-en\#page1

Oster, G.W. (2008). Derailing Design Thinking. International Journal of Leadership Studies, 4(4), 107-115.

Owen, Ch. (2007). Design Thinking: Notes on its Nature and Use. Design Research Quarterly, 2(1), January, 16-27.

Owen, Ch.L. (2006). Design Thinking: Driving Innovation. The Business Process Management Institute, Innovation, September 2006.

Owen, Ch.L. (2005). Design Thinking. What It Is. Why It Is Different. Where It Has New Value. A speech given at the International Conference on Design Research and Education for Future, October 1, 2005.

Pferdt, F.G. (2009). Design Thinking - a (holy) review. EdLab. Teachers College, Columbia University. New York City, 04.30.2009. Retrieved from: http://edlab.tc.columbia.edu/index.php?q=node/2715

Plattner, H. (ed.). (2009). d.school Bootcamp Bootleg. Institute of Design at Stanford. Retrieved from: http:// dschool.stanford.edu/wp-content/uploads/2009/12/bootcampbootleg20091.pdf

Plattner, H. (ed.). (2010). d.school Bootcamp Bootleg. Institute of Design at Stanford. Retrieved from: http:// dschool.stanford.edu/wp-content/uploads/2011/03/BootcampBootleg2010v2SLIM.pdf

Plattner, H., Meinel, C., \& Weinberg, U. (2009). Design Thinking. Innovation lernen - Ideenwelten öffnen. MiWirtschaftsverlag.

Rauth, I., Köppen, E., Jobst, B., \& Meinel, C. (2010). Design Thinking: An Educational Model Towards Creative Confidence. Proceedings of the $1^{\text {st }}$ International Conference on Design Creativity (ICDC 2010), Kobe, Japan, 11, 2010, 1-8.

Ray, B. (2012). Design Thinking: Lessons for the Classroom. Retrieved from: http://www.edutopia.org/blog/ design-thinking-betty-ray

Rittel, H.W.J., \& Webber, M.M. (1972). Dilemmas in a General Theory of Planning. Working paper No.194, presented at the Institute of Urban and Regional Development, University of California, Berkeley, Novemebr 1972.

Rowe, P.G. (1987). Design Thinking. Cambridge MA: MIT Press.

Rylander, A. (2009). Design Thinking as Knowledge Work: Epistemological Foundations and Practical Implications. Design Management Journal, DMI, 7-19.

Schön, D.A. (1983). The Reflective Practitioner: How Professionals Think in Action. New York, N.Y.: Basic Books. Simon, H.A. (1969). The Sciences of the Artificial. $1^{\text {st }}$ edition. Cambridge MA: MIT Press.

Taking Design Thinking to Schools (n.d.). The project of Hasso Plattner Institute of Design (d.school) and the School of Education (SUSE). Retrieved on August 2, 2014 from: http://web.stanford.edu/dept/SUSE/takingdesign/presentations/Taking-design-to-school.pdf

Waloszek, G. (2012). Introduction to Design Thinking. SAP AG, SAP User Experience, September 1, 2012. Retrieved from: http://www.sapdesignguild.org/community/design/design_thinking.asp 